\title{
The Export Value Added and Its Influencing Factors in China's High-tech Manufacturing Exports to the United States
}

\author{
Jiangmin Lou ${ }^{1, a}$, Zhijun Yan ${ }^{2, b}$ \\ ${ }^{1}$ Nanjing University of Science and Technology, Jiangsu 210000, China \\ ${ }^{2}$ Nanjing University of Science and Technology, Jiangsu 210000, China \\ a1511909914@qq.com, ’njust_yanzhijun@163.com
}

Keywords: value added; high-tech manufacturing; influencing factors

\begin{abstract}
This paper employs principal component analysis method and combines the data of the domestic added value of high-tech manufacturing exported to the United States from 2000 to 2014 based on the input-output model to analyze the factors that influence value added. The results show that, first of all, China's trade added value of high-tech manufacturing industry exporting to the United States in the 2000-2014 years began to increase slowly after 2000, and almost ceased to grow in 2008, which may be affected by the financial crisis, and China's export to the United States was thus reduced. Since 2009, trade value added has increased rapidly and it is a manifestation of China's economic growth. Secondly, the scale of trade, value-added of intermediate products, the efficiency of energy conversion, $R \& D$ spending, the degree of division of labor in the global value chain, and the proportion of added value to industry GDP all have a key impact on the value added of trade, among which trade scale plays the most significant impact on high-tech manufacturing industry, which indicates that the high-tech manufacturing industry mainly relies on the expansion of export scale to achieve trade interests, while the export value-adding ability and its international competitiveness need to be improved. It is recommended that China should pay more attention to the development of its high-tech manufacturing industry and improve the utilization and conversion efficiency of resources. At the same time, the nation should improve its division of labor position in the global value chain and rely on technological progress to increase the value of trade rather than its export scale.
\end{abstract}

\section{Introduction}

During the past 20 years, with the rapid development of the global economy and the division of labor in the global value chain, the division of labor and cooperation between countries in various regions has become increasingly important. Transit trade, services trade and processing trade have made connection between regions even closer. This trend has highlighted the limitations of the 
traditional methods of trade statistics. When imported goods are used as intermediate inputs for processing and production, there will be problems of value repeated calculation. In today's economic globalization, this statistical methodology is no longer applicable. Since it cannot reflect the real trade status and level of participation of different nations.

The trade imbalance between China and the United States has existed for nearly two decades, and trade frictions have frequently occurred. Recently, the contradictions between the two countries have come to a head and a full blown trade war is about to take place. According to trade statistics, China is the largest surplus country for the United States. Since China's accession to the WTO, from 2002 to 2016, the nation's trade surplus with the United States has increased nearly 6 times from USD 42.7 billion dollars to USD 250.7 billion. Nonetheless, from the perspective of the industrial value chain, China mainly carries out low value-added manufacturing. For instance, Foxconn makes a profit of USD6.5 for every Iphone that is exported, but it is the unit price USD 178.96 that is included in China's trade statistics. This statistical approach has far overestimated China's real trade interests. At present, various international organizations are working to improve the methodology of trade statistics, aiming to give the most authentic explanation and restoration of trade data.

High-end manufacturing represents high added value and in it exists the huge gap between developing and developed countries. Presently China is also supporting the development of its high-end manufacturing industry, and has opened the IPO green channel for unicorn companies in the four major industries, including the high-end manufacturing industry. Under the circumstances, an in-depth analysis of the influencing factors of the value-added of China's high-tech manufacturing exporting to the USA has far-reaching practical implications, which can shed light on the recognization of the gap between China and the developed countries.

\section{Methodology and Data}

\subsection{Calculation of Domestic Added Value}

According to Zhi Wang's research, a country's total exports can be broken down into four parts, the domestic added value absorbed by the foreign countries (DVA), the domestic added value returned and absorbed by the country(RDV), the foreign added value (FVA), and the pure repetition part (PDC). Among them, the domestic added value absorbed by foreign countries is the real interests to the exporting country.

According to the input-output model formulated by Koopman (2013), the domestic added value of various industries can be calculated. The calculation model of domestic added value is

$$
\mathrm{DVS}=\mathrm{A}_{\mathrm{V}}\left(\mathrm{I}-A^{D}\right)^{-1} X_{f}
$$

In equation(1), $\mathrm{A}^{D}$ is the domestic factor input consumption matrix, $\mathrm{A}_{V}$ is the value-added matrix of each sector, and $\mathrm{X}_{f}$ is the export vector.

This paper relates to the high-tech manufacturing industry, so three high-tech sectors are selected from the world input-output table, they are the manufacturing of computers, electronic and optical products (C26), the manufacturing of power equipment (C27) and the manufacturing of other transport equipment (C30).

\subsection{Analysis of Influencing Factors}

Principal component analysis (PCA) is a statistical method of converting multiple influencing 
factors into fewer but more comprehensive influencing factors. It can transform high-dimensional space into low-dimensional space. The extracted principal component information generally needs to satisfy two conditions: 1 ) that the feature value is greater than 1 and 2) that the cumulative variance contribution rate is greater than $85 \%$. By dividing the data in the principal component load matrix by the square root of the eigenvalues, the coefficients of various indexes in the linear combinations of different principal components are thus determined.

This paper takes the value-added of China's high-tech manufacturing exports to the United States from 2000 to 2014 as the research object. The factors selected are R \& D spending (x1), foreign investment (x2), division of labor in global value chain (x3), trade scale (x4), revealed comparative advantage (x5), value-add's proportion in industry GDP (x6), intermediate products (X7), energy conversion efficiency (x8), and price index (x9).

The data used in this paper comes from the International input-output table provided by the World Input Output Database for the period 2000-2014. China-to-USA industry exports and value-added decomposition results come from the GVCs index system released by the Global Value Chain Research Institute. The data of various influencing factors mainly come from the National Bureau of Statistics and China Statistical Yearbook.

\section{Result Analysis}

\subsection{Analysis of the Domestic Added Value of High-tech Manufacturing Industry}

Based on the input-output model, the trade value added by China in high-tech exports to the US in the past 2000-2014 years is obtained. As shown in Fig.1, it can be found that the trade value-added has slowly increased since 2000 and the growth rate risen faster. This demonstrates the growth momentum of China's economy during this time period. But between 2008 and 2009, the value added of trade almost ceased growing, which may be attributed to the impact of global financial crisis on China's exports to the US. After 2009, the value added of trade has picked up the speed again. The escalating data of trade value added is a manifestation of China's economic growth.

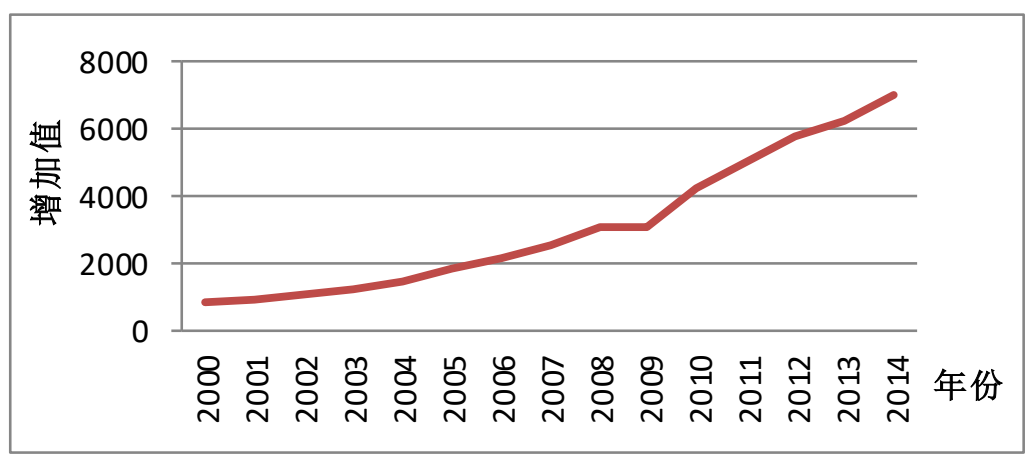

Fig. 1 Chart of the added value

\subsection{Analysis of Influential Factors}

SPSS software is employed to make the correlation analysis of the 9 variables after nondimensionalization. As can be seen in Table 1, the correlation coefficients between most factors is greater than 0.8, indicating that the correlation between factors is strong and positive. The correlation coefficient between R \& D spending (x1), trade scale (x5), revealed comparative advantage (x6), intermediate product (X7) and energy conversion efficiency (x8) is greater than 0.9 , indicating that 
the correlation between the variables is higher. With the development of the economy and the progress of technology, the investment on R \& D and personnel is increasing, and so is the efficiency of production. During the time period, all the factors have been developed rapidly. The production scale and energy conversion efficiency of the high-tech manufacturing industry have been improved, and the comparative advantages of the products expanded.

Table 1 The correlation coefficient matrix

\begin{tabular}{cccccccccc}
\hline & $\mathrm{x} 1$ & $\mathrm{x} 2$ & $\mathrm{x} 3$ & $\mathrm{x} 4$ & $\mathrm{x} 5$ & $\mathrm{x} 6$ & $\mathrm{x} 7$ & $\mathrm{x} 8$ & $\mathrm{x} 9$ \\
\hline $\mathrm{x} 1$ & 1.00 & 0.58 & 0.89 & 0.99 & 0.91 & 0.76 & 0.952 & 0.916 & 0.137 \\
x2 & 0.58 & 1.00 & 0.58 & 0.69 & 0.39 & 0.86 & 0.592 & 0.72 & 0.386 \\
x3 & 0.887 & 0.584 & 1 & 0.897 & 0.65 & 0.874 & 0.985 & 0.881 & 0.429 \\
x4 & 0.986 & 0.688 & 0.897 & 1 & 0.859 & 0.842 & 0.953 & 0.945 & 0.233 \\
x5 & 0.908 & 0.385 & 0.65 & 0.859 & 1 & 0.49 & 0.762 & 0.719 & -0.085 \\
x6 & 0.761 & 0.86 & 0.874 & 0.842 & 0.49 & 1 & 0.851 & 0.881 & 0.537 \\
x7 & 0.952 & 0.592 & 0.985 & 0.953 & 0.762 & 0.851 & 1 & 0.913 & 0.327 \\
x8 & 0.916 & 0.72 & 0.881 & 0.945 & 0.719 & 0.881 & 0.913 & 1 & 0.299 \\
x9 & 0.137 & 0.386 & 0.429 & 0.233 & -0.085 & 0.537 & 0.327 & 0.299 & 1 \\
\hline
\end{tabular}

Since the factors are not independent and collinearity exists, principal component analysis is needed to extract independent factors.

Table 2 Total variance explained

\begin{tabular}{ccccccc}
\hline & Total & Variance\% & Cumulative \% & Total & Variance \% & Cumulative \% \\
\hline 1 & 6.752 & 75.022 & 75.022 & 6.752 & 75.022 & 75.022 \\
2 & 1.342 & 14.912 & 89.934 & 1.342 & 14.912 & 89.934 \\
3 & 0.547 & 6.083 & 96.017 & & & \\
4 & 0.234 & 2.599 & 98.616 & & & \\
5 & 0.088 & 0.98 & 99.596 & & & \\
6 & 0.024 & 0.266 & 99.863 & & & \\
7 & 0.011 & 0.125 & 99.987 & & & \\
8 & 0.001 & 0.01 & 99.997 & & & \\
9 & 0 & 0.003 & 100 & & & \\
\hline
\end{tabular}

Through principal component analysis, we get Table 2 . The eigenvalues, variance percentage and cumulative contribution rate of principal components can be obtained in Table 2. The cumulative contribution rate of variance can indicate the explanatory power of principal components to the subjects. According to the requirement of principal component extraction, two principal components are extracted.

By dividing the rotated factor by the square root of the eigenvalues corresponding to each principal component, the corresponding coefficients of each variable can be obtained. The equations of F1, and F2 can be obtained.

$$
\begin{aligned}
& F_{1}=0.379 x_{1}+0.295 x_{2}+0.374 x_{3}+0.390 x_{4}+0.308 x_{5}+0.363 x_{6}+0.385 x_{7}+0.381 x_{8}+0.144 x_{9} \\
& F_{2}=-0.246 x_{1}+0.294 x_{2}+0.060 x_{3}-0.135 x_{4}-0.470 x_{5}+0.291 x_{6}-0.057 x_{7}-0.016 x_{8}+0.723 x_{9}
\end{aligned}
$$


Table 3 Component matrix

\begin{tabular}{ccc}
\hline Variance & Main ingredient 1 & Main ingredient 1 \\
\hline x1 & 0.955 & -0.285 \\
x2 & 0.743 & 0.341 \\
x3 & 0.943 & 0.07 \\
x4 & 0.983 & -0.156 \\
x5 & 0.775 & -0.545 \\
x6 & 0.915 & 0.337 \\
x7 & 0.97 & -0.066 \\
x8 & 0.961 & -0.019 \\
x9 & 0.362 & 0.837 \\
\hline
\end{tabular}

Two independent components are used instead of 9 factors to analyze the added value of high-tech manufacturing industry. The data of 2000-2014-time period are substituted into equations for analysis. Due to the large difference of data units, some units of data are adjusted and then the adjusted data are analyzed.

It is found that the correlation between F1 and the value added of high-tech manufacturing industry is 0.998 , and they are linearly correlated, while the data of F2 are negatively correlated with the data of high tech manufacturing added value.

By regression analysis of the data of high tech manufacturing value added and the first principal component data, the linear regression equation can be obtained. The regression model is as follows:

$$
\mathrm{Y}=1.095 \mathrm{~F}_{1}+128.213
$$

When the information of the first principal component is substituted into the equation, the regression model of the added value of high-tech manufacturing industry and its influence can be obtained.

$$
\begin{aligned}
& Y=0.403 x_{1}+0.313 x_{2}+0.398 x_{3}+0.415 x_{4}+0.327 x_{5}+0.386 x_{6} \\
& +0.409 x_{7}+0.405 x_{8}+0.153 x_{9}+128.213
\end{aligned}
$$

According to the above regression model, the influencing factors from large to small are trade scale (x4), intermediate product (X7), energy conversion efficiency (x8), R\&D spending (x1), division of labor in global value chain (x3), GDP proportion (x6), revealed comparative advantage (x5), foreign investment (x2), and the price index (x9).

\section{Conclusion and Policy Recommendations}

In this paper, the principal component analysis (PCA) is used to analyze the factors affecting the value added in China's high-tech manufacturing exports to the United States during the 2000-2014 period, and the following conclusions can be drawn.

(1) In 2000-2014, the value added of China's high-tech manufacturing exports to the United States has expanded by more than 8 times, reflecting the rapid growth of China's economy and the results of its continuous development in technology. The trade value added has been increasing slowly since 2000, and the growth rate has performed better. This shows that China's economic development was growing steadily during this period. But in 2008, the value added of trade almost stopped growing, which might be attributed to the global financial crisis that adversely affected China's exports to the US. Since 2009, trade value added has regained its momentum and it is a testament to China's economic development. 
(2) The scale of trade, added value of intermediate products, efficiency of energy conversion, spending on R\&D degree of division of labor in the global value chain, and the value added proportion in the industry GDP all have substantial impact on the value added of trade. In the analysis of this paper, trade scale has the greatest impact on the high-tech manufacturing industry, followed by the intermediate products and energy conversion efficiency. This shows that the nation's high-tech manufacturing industry mainly relies on the expansion of export scale to achieve trade benefits, and the export value-added capability and international competitiveness need to be improved.

Based on our analysis, it can be said that China should attach more importance to the development of high-tech manufacturing industry, and pay more attention to the R\&D activity. Measures should also be taken to improve the efficiency of resource utilization and transformation, and at the same time, to improve the nation's division of labor in the global value chain. On top of this, to deepen the industrial reform and gradually realize the transformation and upgrading of China's economy. Ultimately, China should rely on its technological progress rather than the scale of exports to increase the added value of trade.

\section{References}

[1] Hummels, Ishii, Yi, et al. 2001. The nature and growth of vertical specialization in the world trade. Journal of international Economics.

[2] Robert Koopman, Zhi Wang, Shang-Jin Wei, et al. 2012. Estimating domestic content in exports when Processing trade is pervasive. Journal of Development Economics.

[3] Xu Jiuxiang, Fang Qiyun, et al. 2013. Calculation of China's export value added based on non-competitive input-output table. International Trade Issues, Vol. 11.

[4] Liu Jianjiang, Yang Xizhen, et al. 2011. A Sino-U.S. Trade Balance Study on China's Trade Benefits from the Perspective of Intra-Product Division. International Trade Issues, Vol. 8.

[5] Lin Ling, Yu Juanjuan, et al. 2012. Study on the Measurement of the Export Interests of Chinese Manufacturing Industry and the Influencing Factors. Contemporary Economic Science, Vol. 34

[6] Zeng Yi, Zhang Xianqiao, et al. 2008. Distribution of Sino-US Trade Interests under the Global Production Network System-Based on the Additive Value of Manufacturing Trade. World Economy Research, Vol. 1.

[7] Cheng Wenxian, Fan Xiufeng, et al. 2017. Estimation of value-added by exporters of manufacturing enterprises under the division of global value chain - Data from Chinese micro-enterprise level. China Economic Issues, Vol. 4.

[8] Rong Jinxia, Gu Hao, et al. 2016. Analysis on the Influencing Factors of Division of Work Position in Global Value Chains-Based on the Comparison of Trade Value Added by Countries. International Economic Cooperation, Vol. 5(39-46).

[9] Wang Peizhi, Liu Wenwen, et al. 2014. Analysis of China's Export Trade Structure Changes and Influencing Factors-Based on the Perspective of Technology Added Value. Macro-Economic Research, Vol. 10.

[10] WEI Qianqing, et al. 2013. The calculation of additional value of China's manufactured goods with Ou Sheng Industrial and its influencing factors. Exploration of Economic Issues, Vol. 9. 